\title{
TECHOS DE ARCILLA. REFLEXIONES SOBRE EDUCACIÓN EN EL MODELO DE CORRESPONSABILIDAD
}

Almudena Santaella Vallejo

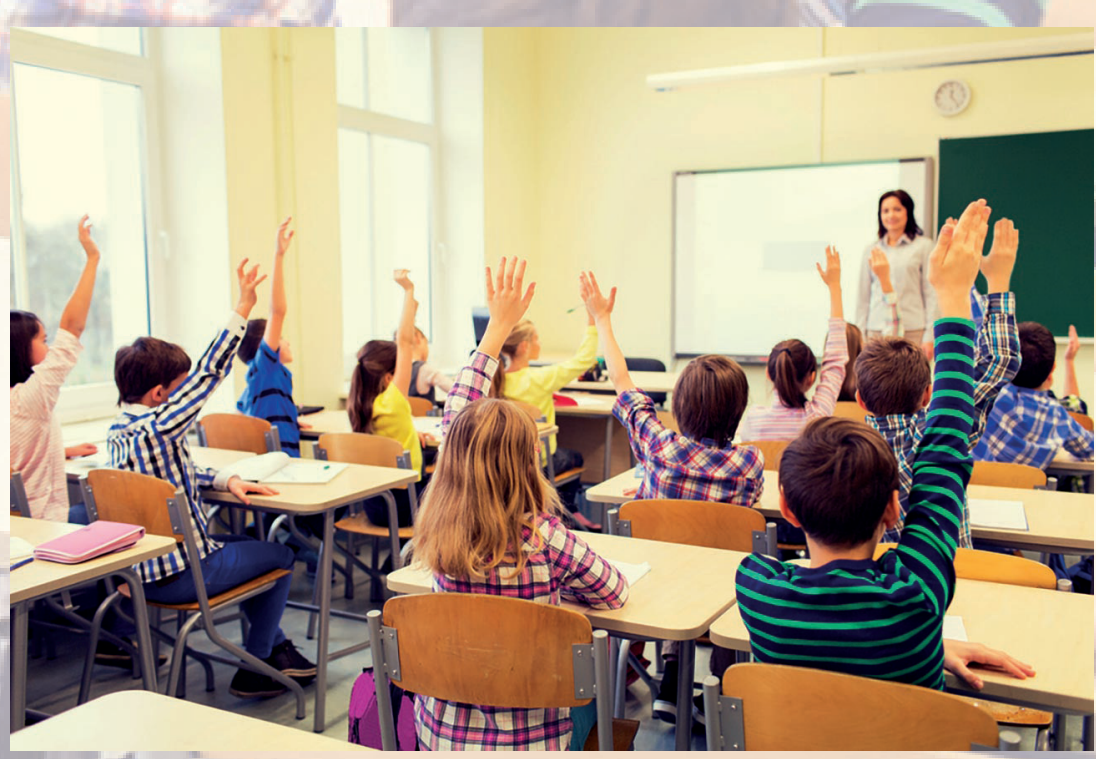





\title{
TECHOS DE ARCILLA. REFLEXIONES SOBRE EDUCACIÓN EN EL MODELO DE CORRESPONSABILIDAD
}

\author{
Almudena Santaella Vallejo \\ UNIVERSIDAD DE ZARAGOZA
}

\section{Resumen}

El modelo educativo de las niñas se ha diseñado en atención al papel atribuido a las mujeres en cada momento de la historia. En la actualidad, a pesar de existir paridad de derechos entre varones y mujeres, la igualdad real no se ha conseguido; las mujeres se encuentran con una serie de limitaciones sociales (techo de cristal) o personales (techo de cemento) que lo impiden. En materia educativa existe otro techo que se llamará "de arcilla", esto es, barreras educativas visibles o invisibles, ausencia de capacidades y aptitudes, que impiden la consecución de la igualdad efectiva y, por su carácter consuetudinario, son difíciles de erradicar y limitan tanto a varones como a mujeres. Se propone la asunción de nuevos valores educativos, como la corresponsabilidad y la inteligencia de género, para proponer diferentes expectativas vitales de unos y otras.

Palabras clave: corresponsabilidad, educación, "techo de arcilla", feminismo, igualdad, inteligencia de género.

La autora: doctoranda en Derecho de la Universidad de Zaragoza. Correo electrónico: almusantaella@ gmail.com

Recibido: 20 de mayo de 2018; evaluado: 20 de junio de 2018; aceptado: 25 de junio de 2018. 


\title{
"CLAY CEILING". REFLECTIONS ON CO-RESPONSABILITY EDUCATION
}

\author{
Almudena Santaella Vallejo \\ UNIVERSIDAD DE ZARAGOZA
}

\begin{abstract}
The educational model for girls has been designed according to the role attributed to women in every moment of history. At present, despite the exiting parity of rights between men and women, real gender equality has not yet been achieved. Women still find a series of social limitations ("glass ceiling") or personal limitations ("cement ceiling") that prevent them from being equal. In terms of education, there exists another type of ceilings that we will call "clay ceiling," which refers to visible or invisible educational barriers, as well as to the absence of capacities and aptitudes that impede the achievement of real equality; and which, due to their customary nature, are difficult to eradicate and place limits on both men and women. This paper proposes the acceptance of new educational values, such as co-responsibility and gender intelligence, in order to develop different vital expectations for both.
\end{abstract}

Keywords: co-responsibility, education, "clay ceiling," feminism, equality, gender intelligence.

About the author: PhD Candidate in Law at the Universidad de Zaragoza. Email: almusantaella@ gmail.com

Received: May 20, 2018; reviewed: June 20, 2018; accepted: June 25, 2018. 


\section{Introducción}

El modelo de corresponsabilidad entre varón y mujer consiste en el reparto equilibrado de derechos y deberes productivos — asignados tradicionalmente al varón-y reproductivos — asignados tradicionalmente a la mujer —, esto es, las tareas domésticas y las responsabilidades familiares (organización, cuidado, educación y afecto a las personas dependientes en el hogar), con el fin de distribuir de manera justa los tiempos de vida de mujeres y hombres.

Pese a que la reforma del Artículo 68 del Código Civil por la Ley 13/2005, del 1 de julio, incluyó el deber de corresponsabilidad entre los cónyuges, este carece de eficacia jurídica, ya que no viene acompañado de la correspondiente sanción en caso de incumplimiento; por ello se consideraría una norma natural y no jurídica, meramente declarativa sobre las obligaciones conyugales que, en muchas ocasiones, deriva en dobles jornadas laborales que soporta la mujer, desencuentros y conflictos en la convivencia familiar.

Tras casi cuarenta años de vigencia del Artículo 14 de la Constitución española de 1978 y diez de la Ley Orgánica 3/2007 para la igualdad efectiva entre mujeres y hombres, la igualdad real todavía no se ha logrado en el ámbito público ni en el seno de la pareja. Así concluyen varios autores como Del Valle Loroño ${ }^{1}$ C Chinchilla, Jiménez y Grau, ${ }^{2}$ al constatar, entre otros puntos:

1. Mayor participación activa, física y rutinaria de la mujer en las responsabilidades domésticas y de cuidado de los hijos, aunque ambos trabajen jornada completa.

2. El "micromachismo" como una realidad muy presente en el seno de la relación conyugal. ${ }^{4}$ Cuanto mayor grado educativo, mayor implicación del cónyuge o pareja, por lo que la educación facilita la igualdad y la corresponsabilidad.

1 Ana Irene Del Valle Loroño, "Inercias de género en la gestión de la vida profesional y familiar. Dos generaciones de familias de doble carrera" (Tesis doctoral, Universidad de Deusto, 2016), 501-518.

2 Nuria Chinchilla, Esther Jiménez y Marc Grau, Maternidad y trayectoria profesional en España (Pamplona: Universidad de Navarra, Estudio, 2017), 27-33.

3 El término micromachismo se acuña a partir de conceptos de Foucault (microrrelaciones de poder) y Bourdieu (violencia simbólica). Hace referencia a las injusticias de la vida cotidiana, tiranías que pasan desapercibidas por el carácter de normalidad que se les da. Se basan en un paradigma mecanicista en el que se aceptan implícitamente situaciones de desigualdad de la mujer con respecto al hombre.

4 Bonino presenta diferentes tipos de micromachismos: los utilitarios (apariencia de implicación), los encubiertos (falta de experiencia), los coercitivos (control) y los de crisis (hipercontrol). Luis Bonino, "Los micromachismos", La Cibeles, núm. 2 (2004): 1-6. 
3. Tanto mujeres como hombres renuncian y reducen el número de hijos que les gustaría tener $(2,52)$ frente a los que en realidad tienen $(1,32)$. Esto se debe a obstáculos que encuentran en la sociedad o en la empresa (techo de cristal) y a la falta de apoyo de los Gobiernos. En la mayoría de ocasiones, dicha carencia es suplida por la ayuda de familiares, fundamentalmente ascendientes.

4. Acoso laboral por maternidad en cuanto al proceso de selección, proyección y promoción profesional.

5. Horarios irracionales: se produce un desajuste entre el calendario y el horario escolar y laboral. Esto dificulta la conciliación entre la vida laboral y familiar. ${ }^{5}$

6. "Techos de cemento", esto es, creencias de las mujeres sobre sí mismas y sus carencias, que limitan y reducen el desarrollo en sus trayectorias vitales. ${ }^{6}$

7. Las mujeres de la muestra tienen un grado de estudios ligeramente superior a sus parejas.

8. Tanto varones como mujeres declaran que la familia es más importante que el trabajo, pero son ellas las que hacen más sacrificios laborales a favor de la familia, mientras sus cónyuges se dedican principalmente al trabajo.

9. Corrobora la brecha salarial de género: en un $72 \%$ de las parejas la mujer tiene menores ingresos.

Hablar de corresponsabilidad en España supone adentrarse en una de las metas y aspiraciones para alcanzar la igualdad efectiva entre mujeres y hombres del siglo XXI. Hoy en día se comprueba una brecha entre la legislación —-formalmente igualitaria— y la realidad vivenciada por las mujeres. Pese a que ley otorga igual acceso a la educación y a las oportunidades, el cambio cultural no se ha producido. ¿Cuál es el motivo de la resistencia a considerar la igualdad de oportunidades? ¿Existe alguna limitación que impide esta evolución en el sistema educativo español?

5 La Comisión nacional para la racionalización de los horarios españoles (ARHOE) se constituyó en 2003, con el objetivo de fomentar unos horarios laborales más humanos, adaptados a las necesidades sociales y económicas actuales.

6 La barrera personal femenina más citada es la falta de formación en áreas tradicionalmente masculinas (matemáticas, informática e ingeniería), seguida por tres barreras de confianza en uno mismo: infravaloración, temor al fracaso y falta de confianza. 
Históricamente, el modelo educativo se ha diseñado en atención al papel o rol atribuido a varones y mujeres en cada momento. Por tanto, encaminamos nuestra indagación hacia las leyes educativas existentes en España durante el siglo XX, que servían para sostener un modelo de relación varón-mujer determinado, con el objetivo de dilucidar por qué hoy, a pesar de una educación igualitaria para unos y otras, continúan las desigualdades sociales en el seno de la relación conyugal; por qué se produce lo que el sociólogo americano Erik O. Wright ${ }^{\top}$ denomina "utopía real". ${ }^{8}$

El objetivo es constatar la existencia de los "techos de arcilla", término que utilizaremos para designar las barreras educativas visibles - tangibles o estructurales- 0 invisibles —en cuanto presencia o ausencia de valores educativos- que impiden la consecución de la igualdad real.

\section{Modelos de relación varón-mujer}

Elósegui ${ }^{9}$ describe y desarrolla tres modelos teóricos coexistentes en la realidad actual de la población española sobre las relaciones entre varones y mujeres. Estos esquemas se han ido forjando a lo largo de la historia y fueron refrendados por leyes que configuraban el papel de la mujer en el ámbito público, así como su rol dentro de la familia y de la sociedad.

\subsection{Modelo desigualitario}

La mujer depende y está subordinada al varón. Se justifica por el determinismo biológico: las diferencias sexuales se extienden al ámbito sociocultural y definen los papeles o roles sociales. Mientras al varón le corresponden los derechos productivos, se reserva a la mujer el ámbito doméstico, el papel reproductivo. ${ }^{10}$

Archon Fung y Erik Olin Wright, Deepening Democracy. Institutional Innovations in Empowered Participatory Governance (Nueva York: Verso, 2003).

8 Ideas y realidad presentan un contrasentido y reflejan una paradoja entre unas pautas de empleo y de actitudes de género cada vez más simétricas frente a unas prácticas de división del trabajo doméstico y de cuidados aun mayoritariamente tradicionales.

9 María Elósegui Itxaso, Diez temas de género. Hombres y mujeres ante los derechos productivos y reproductivos (Madrid: Ediciones Internacionales Universitarias, 2011), 49-96.

10 Hoy, este modelo está superado en el ámbito legislativo y teórico, pero persiste en determinados ámbitos de la realidad social española: en núcleos generacionales educados en la época franquista, la generación del baby boom (nacidos entre 1945 y 1964); en áreas rurales; en núcleos culturales de inmigrantes provenientes de América Latina o países de cultura islámica o núcleos con bajo nivel educativo. En estos sectores de la sociedad se mantiene y se reproduce ese modelo por la educación en el contexto familiar. 


\subsection{Modelo igualitario}

Defiende la premisa de la separación entre lo biológico y lo cultural. Tiene su origen en la autora Simone de Beauvoir. ${ }^{11}$ La mujer, para conseguir equipararse al varón, tenía que "prescindir de lo específicamente femenino, asumiendo como válidos los esquemas propuestos y desarrollados por los varones". ${ }^{12}$ La consecuencia lógica de esta premisa, por lo que atañe al Legislador, es que no debe haber distinción alguna basada en la diferencia sexual, porque esta no existe. ${ }^{13}$ Los sexos, por tanto, se homologan en derechos. ${ }^{14}$

\subsection{Modelo de corresponsabilidad}

Este tercer modelo es propuesto por Elósegui ${ }^{15}$ como el más justo. Considera que la perspectiva de género es adecuada para describir los aspectos culturales que rodean la construcción de las funciones del hombre y de la mujer en el contexto social, las cuales han sido atribuidas culturalmente a cada sexo, pero son intercambiables en algunos aspectos, ya que dependen de los estereotipos formados por el grupo social, por costumbres o por la educación. ${ }^{16}$ En otras ocasiones, el género, lo cultural, se asienta y se fundamenta en la condición sexuada original de cada persona. ${ }^{17}$

Martínez Priego ${ }^{18}$ explica las tres dimensiones de la relación varón-mujer: la reciprocidad, la complementariedad y la corresponsabilidad, aspectos necesarios para la consecución de una vinculación ponderada entre varón y mujer. La

11 Influenciada por las teorías comunistas de Marx y Engels y por el existencialismo de Sartre, De Beauvoir defendió la idea de que la mujer no nace, sino que se hace: llega a serlo. Simone de Beauvoir, Le deuxième sexe (París: Gallimard, 1949).

12 Paloma Durán y Lalaguna, Los límites del derecho (Granada: Comares, 1996), 31.

13 "La visión igualitarista o asimilacionista no da relevancia a las diferencias sexuales". Carmen Sáez Lara, Mujeres y mercado de trabajo: las discriminaciones directas e indirectas (Madrid: Consejo Económico y Social de España, 1994), 23.

14 La generación X (los nacidos entre 1965 y 1981), educada en la década del setenta con la Ley general de educación y financiamiento de la reforma educativa 14/1970, del 4 de agosto y los denominados millenials, nacidos entre 1982 y 1994, cuya educación es fruto de las reformas educativas LODE (ampliación de la enseñanza obligatoria hasta los 16 años), LRU (autonomía universitaria) y Logse en 1990.

15 María Elósegui Itxaso, "Educar en la corresponsabilidad entre mujeres y hombres. La igualdad necesaria", Revista General de Derecho Canónico y Derecho Eclesiástico del Estado, núm. 20 (2009): 1-28.

16 Elósegui Itxaso, Diez temas de género, 85-86.

17 La generación Z (nacidos desde 1995 hasta la actualidad) ha sido educada con la LOE de 2006 (con la polémica asignatura de Educación para la Ciudadanía y los Derechos Humanos) y la Lomce de 2013 inspiradas en este modelo.

18 Consuelo Martínez Priego, "Dinamismo familiar interno" en La familia y sus ámbitos. Cinco ensayos en torno a la familia desde la persona, ed. Consuelo Martínez Priego y Miguel Ruenmayor (Ciudad de México: Porrúa, 2016), 25-58. 
complementariedad corporal, psíquica y social, por la que las diferencias se destacan como cualidades positivas y no como desigualdades, se vincula a la corresponsabilidad, "cuyos roles —más estables unos, más circunstanciales otros— no desliga a ninguno de los dos, varón y mujer, del contenido total del proyecto común". ${ }^{19}$ Señala que madre y padre son corresponsables de la dinámica familiar interna y señala que en este punto hay:

[... . un claro déficit educativo. La familia y la sociedad en general, no facilitan al varón que la paternidad y la familia formen parte de su proyecto personal con la misma fuerza con lo que lo hace en la mujer. Por su parte la mujer tiende a relegar por necesidad su vida profesional $\left[\ldots . .{ }^{20}\right.$

El modelo de corresponsabilidad posibilita a la mujer su actuación en la esfera pública y su desarrollo profesional. Se desbaratan así los techos de cristal y se enriquecen ambos espacios — público y doméstico— con la intervención y el modo propio de ser varón o mujer. ${ }^{21}$

\section{Fases históricas en España vinculadas a modelos educativos de relación varón-mujer}

A raíz de la Revolución francesa surgieron en Europa los primeros sistemas educativos nacionales. En España, la Constitución de 1812 incorporó la idea de que el Estado debía intervenir en la organización, la financiación y el control de la educación, por lo que fue utilizada como instrumento ideológico. La Ley de instrucción pública del 9 de septiembre de 1857 (Ley Moyano) reconoció por primera vez en el país el derecho a la educación obligatoria para niños y niñas de 6 a 9 años. Comenzó la creación, por parte de los Ayuntamientos, de una escuela dual, con currículos diferenciados y la coexistencia de la educación privada, seglar y religiosa. A pesar del esfuerzo, el alto absentismo escolar existente a principios del siglo $\mathrm{XX}^{22}$ se reflejó en el analfabetismo de un 69 \% de la población femenina mayor de 10 años.

19 Martínez Priego, "Dinamismo familiar interno", 46-47.

20 Martínez Priego, "Dinamismo familiar interno", 47.

21 Castilla descubre y explica con preposiciones la condición sexuada de la persona: al varón le corresponde la preposición "desde", porque parte desde sí para darse a los demás; a la mujer le corresponde la preposición "en", pues se abre al dar en acogida en sí misma. La persona varón se describe "ser con desde" y la persona mujer, "ser con en". Blanca Castilla y Cortázar, Persona y género. Ser varón y ser mujer (Madrid: Ediciones internacionales universitarias, 1997).

22 María Cruz Del Amo, "La educación de las mujeres en España: de la amiga a la universidad", Participación educativa, núm. 11 (2009): 8-22. 
Durante el siglo XX, la legislación sostuvo distintos modelos educativos que respaldaban un prototipo determinado de relación varón-mujer determinado. Distinguiremos cuatro fases históricas, con referencia a las leyes educativas de cada una de ellas, para analizar los "techos de arcilla" que limitaban la consecución de la igualdad efectiva.

\subsection{Fase inicial transitoria (1900-1939)}

Abarca la etapa política del reinado de Alfonso XIII y la II República. La mujer consiguió acceso a la educación y se reconoció la igualdad de derechos en la Constitución de 1931. Con esto se puso en cuestión el modelo desigualitario de varón-mujer.

El Real Decreto del 26 de octubre de 1901 implantó programas comunes para ambos sexos en la enseñanza primaria y más tarde, con el Real Decreto del 2 de septiembre de 1902, se nombraron por vez primera vocales mujeres en las juntas provinciales y municipales de instrucción pública. La Ley del 23 de junio de 1909 extendió la escolaridad obligatoria hasta los 12 años. Por Real Decreto del 3 de junio de 1909 se creó la Escuela de estudios superiores del magisterio. La Real Orden del 8 de marzo de $1910^{23}$ abrió las puertas de acceso a la universidad para las mujeres. La coeducación se inició con una Real Orden de 1911, cuya aplicación estuvo muy limitada debido a la presión social en contra que, en unos casos, exponía razones morales y, en otros, motivos prácticos. En 1915 se inauguró la Residencia de señoritas en Madrid, la primera institución social universitaria establecida en España para mujeres graduadas y, en 1918, el mismo organismo creó el Instituto-escuela, centro de estudios primarios y secundarios de carácter mixto.

El Real Decreto de 1927, durante el mandato de Primo de Rivera, fue el primer paso para la separación de sexos en el bachillerato y en 1929, con el Real Decreto del 14 de noviembre, se crearon los dos primeros institutos femeninos: el Infanta Beatriz en Madrid y el Infanta Cristina en Barcelona.

El Gobierno de la II República consideró la educación como asunto prioritario, por lo que en la Constitución de la II República de $1931^{24}$ se proclamó el derecho

23 Deroga la anterior del 11 de junio de 1888, que exigía a las mujeres permiso previo de las autoridades académicas para poder matricularse en los centros de enseñanza oficial.

24 "El servicio de la cultura es atribución esencial del Estado, y lo prestará mediante instituciones educativas enlazadas por el sistema de la escuela unificada". 
a ella. Defendió la escuela única, la gratuidad y la obligatoriedad de la enseñanza primaria, la libertad de cátedra y la laicidad de la enseñanza. Los profesores y catedráticos eran funcionarios y se facilitó a todos los españoles económicamente necesitados el acceso a todos los grados de enseñanza, de modo que solo estuvieran condicionados por la aptitud y la vocación..$^{25}$

Las deliberaciones en torno a la educación femenina evolucionaron en esta fase, desde cuestionar la necesidad de instruir o no a la mujer por su papel educativo de futuros ciudadanos hasta debatir sobre el modelo de enseñanza dual o única, la diferenciación de asignaturas y contenidos y la posibilidad de acceso a estudios superiores universitarios - lo que concluiría con el ejercicio de una profesión-. La gran polémica se enfocó en la coeducación. ${ }^{26}$ El hecho de compartir aulas, materias y profesores era percibido por muchos sectores como contrario a la moral y a las buenas costumbres. Lo defendieron institucionalistas, anarquistas y socialistas y fue rechazada por los sectores conservadores; los argumentos se apoyaban más en ideología política que en pedagogía científica. El modelo de escuela mixta reconocido en la Constitución de 1931 no llegó a instaurarse, ya que la victoria del Frente Popular en 1936 precipitó el alzamiento y la guerra civil.

Los "techos de arcilla" en esta fase eran visibles y estructurales: limitaban la igualdad de oportunidades, con base en el pensamiento dominante de la época — reduccionismo biológico- que asignaba y educaba según el sexo. A la mayoría de las mujeres se le privó de educación o se la educó orientada a su rol en el ámbito doméstico.

La enseñanza primaria será gratuita y obligatoria.

Los maestros, profesores y catedráticos de la enseñanza oficial son funcionarios públicos. La libertad de cátedra queda reconocida y garantizada.

La República legislará en el sentido de facilitar a los españoles económicamente necesitados el acceso a todos los grados de enseñanza, a fin de que no se halle condicionado más que por la aptitud y la vocación. La enseñanza será laica, hará del trabajo el eje de su actividad metodológica y se inspirará en ideales de solidaridad humana.

Se reconoce a las Iglesias el derecho, sujeto a inspección del Estado, de enseñar sus respectivas doctrinas en sus propios establecimientos". España, Constitución Politica (Madrid: Tecnos, 1931), art. 48.

25 Ministerio de Educación y Cultura y Deporte, Evolución del sistema educativo español (Madrid: Autor, 2004), 5.

26 Rosa María Capel Martínez, El trabajo y la educación de la mujer en España (1900-1930), 2a ed. (Madrid: Ministerio de Cultura, 1986). 


\subsection{Fase regresiva: educación para afianzar roles sociales en función del sexo}

Durante el régimen franquista y hasta la aprobación de la Constitución de 1978 (1939-1978), las mujeres perdieron ciudadanía política —a la par que los varones_y derechos sociales y civiles y se reafirmaron los roles consuetudinarios o clásicos. Se afianzó el modelo de relación desigualitario, en el que la mujer se subordinaba y dependía del varón. Se considera una regresión respecto a los derechos obtenidos en la fase anterior, con la Constitución de 1931.

La educación femenina en la época franquista era obligatoria, diferenciada, orientada a fortalecer el rol de la mujer como madre y esposa y estaba fuertemente impregnada de la religión y la moral católicas. Esta educación obligatoria se garantizaba mediante las leyes educativas, la escolarización y la Sección Femenina ${ }^{27}$ dirigida inicialmente por Pilar Primo de Rivera. ${ }^{28}$ Los dos términos estructurales que definen la doctrina de la Sección Femenina son el nacional-catolicismo y el nacional-sindicalismo. ${ }^{29}$ La tutela ejercida sobre las mujeres fue de gran importancia, ya que en sus inicios toda mujer debía de pasar por la organización al menos durante seis meses, asistir a sus locales, cursos y actividades. Además, las alumnas en edad escolar tendrían como asignaturas impartidas por la Sección Femenina: Hogar, Educación Física y más adelante, Formación del Espíritu Nacional. Supuso un gran impulso en las áreas rurales.

Respecto a la educación escolar, la legislación fue utilizada en una primera etapa ${ }^{30}$ como arma ideológica. La Ley del 20 de septiembre de 1938 impuso medidas que revocaban las implantadas durante la II República a favor de la escuela laica, obligatoria y coeducativa, para consolidar el modelo conservador. El 29 de julio de 1943 se promulgó la Ley que regula la ordenación de la universidad: el rector

27 El Decreto del 28 de diciembre de 1939 regulaba las funciones de la Sección Femenina; le confiaba la formación política y social de la mujer española y le adjudicaba el servicio social.

28 María Fernanda Del Rincón, "Mujeres azules de la Sección Femenina: formación, libros y bibliotecas para el adoctrinamiento político en España (1939-1945)”, MÉI: Métodos de información I, núm. 1 (2010): 59-81.

29 Pilar Rebollo Mesas, "El servicio social de la mujer de Sección Femenina de Falange. Su implantación en el medio rural" en Nuevas tendencias historiográficas e historia local en España, coord. Miguel Ángel Ruiz Carnicer y Carmen Frías Corredor (Huesca: Universidad de Zaragoza, 2001), 297-316.

30 "En los primeros años, la educación sólo interesa al gobierno como vehículo trasmisor de la ideología, sin importarle en exceso su organización y estructura interna. Así proliferan decretos y órdenes ministeriales con una sola idea: La educación debe ser católica y patriótica. Hay por tanto un rechazo frontal a la política educativa de la República". Ministerio de Educación y Cultura y Deporte, Evolución del sistema educativo español, 5 . 
debía ser miembro de la Falange Española Tradicionalista (FET) y de las Juntas de Ofensiva Nacional Sindicalista (JONS) y, para ejercer, los profesores universitarios requerían una certificación de la Secretaría General del Movimiento que acreditara su adhesión a los principios del Estado. La Ley de educación primaria del 17 de julio de 1945 y la Ley de formación profesional industrial de 1949 terminaron por modelar en esta línea de adoctrinamiento ideológico propio de la posguerra.

En la segunda etapa, en la década del cincuenta, la legislación cedió en cuanto adoctrinamiento político para favorecer el técnico-pedagógico: la Ley sobre ordenación de la enseñanza media de 1953 generalizó la educación secundaria hasta los 14 años, pero mantuvo la diferenciación entre sexos. También se promulgaron la Ley de construcciones escolares de 1953 y la Ley de julio de 1957 sobre enseñanzas técnicas, que incorporaron las escuelas de ingeniería y arquitectura a la universidad.

En la década del setenta se advirtió una línea de apertura pedagógica. La Ley general de educación y financiamiento de la reforma educativa 14/1970 del 4 de agosto reflejaba los cambios sociales producidos en España tras el desarrollo industrial de esos años, al reconocer la escolaridad obligatoria para niños y niñas hasta los 14 años y la igualdad de ambos sexos en el sistema escolar —lo que derivó, en la década del ochenta, en la matriculación universitaria de un 50 \% de alumnas-. Conjugó, por un lado, el principio de la confesionalidad católica propugnado por el Fuero de los españoles, ${ }^{31}$ con el principio de libertad religiosa afirmado en la Declaración del Concilio Vaticano II, ${ }^{32}$ en Dignitatis Humanae. Se modificaron los tres niveles de educación tradicionales para establecer otros cuatro: preescolar, educación general

31 "Artículo $5^{\circ}$. Todos los españoles tienen derecho a recibir educación e instrucción y el deber de adquirirlas, bien en el seno de su familia o en centros privados o públicos, a su libre elección. El Estado velará para que ningún talento se malogre por falta de medios económicos.

Artículo $6^{\circ}$. La profesión y práctica de la Religión Católica, que es la del Estado español, gozará de la protección oficial. Nadie será molestado por sus creencias religiosas ni el ejercicio privado de su culto. No se permitirán otras ceremonias ni manifestaciones externas que las de la Religión Católica". España, "Fuero de los españoles" (Madrid: Boletín Oficial del Estado No. 199, 18 de julio de 1945), arts. 5-6.

32 La libertad religiosa fue siempre un tema de reflexión vinculado con los derechos humanos. El Concilio Vaticano II tiene una declaración entera dedicada a esta problemática. Allí se afirma que "la verdad no se impone de otra manera, sino por la fuerza de la misma verdad, que penetra suave y fuertemente en las almas". Pablo VI, Dignitatis Humanae. Concilio Vaticano II (Roma, 7 de diciembre de 1965), 1.

La libertad del hombre rechaza toda imposición, lo cual no significa que rechace toda verdad, sino que su misma dignidad exige que lo dejen buscar sin coacciones, como mejor sepa y pueda. La libertad religiosa "consiste en que todos los hombres han de estar inmunes de coacción, tanto por parte de individuos como de grupos sociales y de cualquier potestad humana, y esto de tal manera que, en materia religiosa, ni se obligue a nadie a obrar contra su conciencia, ni se le impida que actúe conforme a ella en privado y en público". Pablo VI, Dignitatis Humanae, 2. Porque "la verdad debe buscarse de modo apropiado a la dignidad de la persona humana y a su naturaleza social". Pablo VI, Dignitatis Humanae, 3. 
básica (EGB), bachillerato unificado polivalente (BUP) y enseñanza universitaria. Esta ley reconoció la función docente del Estado en la planificación de la enseñanza y en la provisión de puestos escolares y dio fin al principio de subsidiariedad del Estado frente a los padres en materia educativa.

Los "techos de arcilla" existentes en esta fase son visibles — diferente contenido lectivo-y estructurales — aulas separadas — y también invisibles —en este caso, disuasivos- en cuanto a la exaltación de los valores tradicionales como orden más natural. Predominaba la idea de que la mujer culta debía dedicarse al cuidado de los hijos y que ello "era en muchos casos notablemente superior a la aportación al producto social que la mujer pudiera efectuar con su incorporación a las unidades económicas de producción". ${ }^{33}$ Por esto, el sistema educativo estaba diseñado para que las mujeres desistieran del acceso a la educación universitaria. Hasta la década del setenta, un 70 \% de mujeres se conformaba con una educación básica y media, pero a pesar de la fuerte ideologización del sistema educativo al que estaban sometidas, las mujeres de la burguesía española de la época franquista fueron accediendo a la educación superior, poco a poco, con un siglo de retraso respecto a las mujeres burguesas francesas, alemanas o inglesas.

\subsection{Fase evolucionada: sistema educativo igualitario}

En la etapa constitucional, comprendida entre los años 1978-1999, se produjo el reconocimiento de la plena ciudadanía política, civil y social para las mujeres, de la mano del Artículo 14 de la Constitución de 1978. Así apareció el modelo igualitario entre varón y mujer con la presencia y participación masiva de ellas en el ámbito público y en el mercado laboral asalariado, que estaba regulado y organizado con las normas y funciones propias del varón.

La Constitución de 1978 recogió por primera vez una proclamación sobre el derecho a la educación y a la libertad de enseñanza en el Artículo 27. En este se marcaron los principios generales de la legislación de ese período igualitario en materia educativa. Su formulación dio pie a una serie de leyes: la Ley Orgánica 11/1983, del 25 de agosto, de reforma universitaria; la Ley Orgánica 8/1985, del 3 de julio, reguladora del derecho a la educación; la Ley Orgánica 1/1990, del 3 de octubre, de ordenación general del sistema educativo; la Ley Orgánica 9/1995, del 20 de noviembre, de la participación, la evaluación y el gobierno de los centros docentes.

33 Ministerio de Educación, La educación en España (base para una política educativa) (Madrid: Autor, 1969). 
La Ley orgánica reguladora del derecho a la educación (LODE) de 1985 desarrolló el Artículo 27 de la Constitución, para incidir en la consecución de una enseñanza básica, obligatoria y gratuita, en el pleno desarrollo de la personalidad del alumno, en la formación en el respeto y en el ejercicio de la tolerancia y de la libertad, en la adquisición de conocimientos, hábitos y técnicas que capaciten para la actividad profesional y la participación activa en la sociedad, así como en la formación para la paz y la cooperación. Esta Ley distinguió entre centros públicos, privados — que funcionan en régimen de mercado- y centros de titularidad privada sostenidos con fondos públicos, denominados centros concertados.

La Ley Orgánica 1/1990 de ordenación general del sistema educativo (Logse) reguló la estructura y la organización del sistema educativo en sus niveles no universitarios - primaria ESO y bachillerato-. En ella se reiteraron los principios y derechos reconocidos en la Constitución y en la LODE. En su Artículo 2.3 c) se refiere a "La efectiva igualdad de derechos entre los sexos, el rechazo a todo tipo de discriminación y el respeto a todas las culturas".

Durante esta etapa, "los techos de arcilla" visibles y estructurales desaparecieron, pero se mantuvieron los invisibles: la igualdad se presentó como igualitarismo. En efecto, se garantizaba el pleno acceso a la educación de la población femenina, al reconocer por ley la igualdad de oportunidades y se impulsó el desarrollo de hábitos y técnicas que capacitaran para la actividad profesional y la participación activa en la sociedad. Quedó un vacío: la educación para desarrollar hábitos y técnicas que capacitaran para la actividad en el ámbito privado: propiciar una vida familiar y personal. Este ámbito quedó omitido tanto para los varones como para las mujeres. El sistema educativo se enfocó exclusivamente en la actuación en el ámbito público, lo que originó un cambio ante la distribución de los derechos productivos y reproductivos: ellas asumieron el rol público además del rol doméstico, pero como demuestra el estudio, muchos de ellos siguieron siendo objeto pasivo del cambio fundamental que había experimentado el colectivo femenino y se perpetuaron las mismas reglas de actuación en el ámbito público y ausencia en el familiar y doméstico. Este asunto imposibilitó el cambio cultural necesario para que se diera el paso al modelo de corresponsabilidad.

\subsection{Fase de igualdad real: 1999-actualidad}

A partir de 1999 se comenzó a legislar en España con el fin de implementar el modelo de corresponsabilidad. La Ley 39/1999, del 5 de noviembre y la Ley 
Orgánica 3/2007, del 22 de marzo, de igualdad efectiva de mujeres y hombres, tuvieron como objetivo a corto plazo que la igualdad se realizara tanto en el ámbito público como en el privado. El Estado solo debía intervenir para concienciar o por medio de la educación en las escuelas.

La Ley Orgánica de educación (LOE) fue publicada en el BOE en mayo de 2006 y aprobada en el Congreso con amplia mayoría por el apoyo de PSOE, CiU, ERC, PNV, ICV, CC, y EA. El PP votó en contra e IU se abstuvo. Por esta Ley se compromete en el Artículo 23 c, a: "Valorar y respetar la diferencia de sexos y la igualdad de derechos y oportunidades entre ellos. Rechazar los estereotipos que supongan discriminación entre hombres y mujeres".

Aunque la crítica más amplia a esta Ley estaba basada en la menor exigencia al alumnado, por la posibilidad de pasar de curso con materias suspendidas, dos de los puntos más polémicos fueron incluir como voluntaria la asignatura de Religión - aunque de oferta obligatoria para los centros educativos - y la inclusión de la nueva asignatura de Educación para la Ciudadanía y los Derechos Humanos como materia obligatoria y evaluable. Muchos lo consideraron como una incursión del Estado como adoctrinador en la moral de los estudiantes y otros defendían la necesidad de concienciar a la población frente a una participación más activa, comprometida y responsable en la esfera pública.

La idea de que la educación reglamentada escolar debía estar orientada al empleo público y encargarse estrictamente de formar las habilidades y destrezas instrumentales chocaba con el papel de la institución familiar, ${ }^{34}$ encargada de educar en afectos, valores y actitudes. ¿Qué rol educativo correspondía a los padres y qué rol al Estado en tanto a trasmisor de valores? Comenzó el debate sobre el papel de la familia y la escuela, en un momento en el que la función socializadora de la familia parecía entrar en declive por el aumento de familias monoparentales, la aparición de distintas formas de convivencia familiar y la inmigración, que conlleva una falta de identidad cultural respecto a los valores constitucionales. Todo esto proporcionó al Legislador un argumento y una oportunidad para reivindicar el papel del Estado y su rol educativo en el ámbito cívico y democrático.

La Ley Orgánica para la mejora de la calidad educativa 8/2013, del 9 de diciembre, fue la propuesta de reforma de la LOE y de la Logse. En ella se volvió a dar plena

34 Martínez Priego, "Dinamismo familiar interno", 30-31. 
validez académica a la asignatura de Religión, se recuperaron las pruebas externas de evaluación o reválidas, se exigió más a la hora de otorgar becas universitarias y se permitió concertar con los colegios de educación diferenciada y personalizada.

A pesar de que en la declaración de principios que inspiraron esta Ley se enunció en su Artículo 1 "El desarrollo de la igualdad de derechos y oportunidades y el fomento de la igualdad efectiva entre hombres y mujeres", no se encuentra propuesta ni medida concreta para ello en las asignaturas, en los objetivos curriculares o en la metodología. ${ }^{35}$ En este sentido, es muy útil la distinción que Cuban hizo años atrás, en 1988, entre cambios pedagógicos de primer y de segundo orden. ${ }^{36} \mathrm{La}$ diferencia entre el primer y el segundo orden radica en la profundidad de los cambios: mientras los de primer orden no modifican substancialmente los procesos, los de segundo orden permiten transformarlos de modo radical. Estos cambios de segundo orden no se han producido, pues no ha habido un cambio de fondo en la cultura de corresponsabilidad. No se educa ni a varones ni a mujeres para afrontar sus responsabilidades domésticas. Los "techos de arcilla", en esta ocasión, son intangibles e invisibles, puesto que denotan la ausencia en la educación de los nuevos valores necesarios para consolidar el modelo de pareja actual: el de la igualdad en la diferencia, también conocido como corresponsabilidad.

\section{Conclusiones}

Con la revisión de las leyes educativas del siglo XX se constata que estas inciden en cada modelo educativo acerca del rol del varón y de la mujer en la sociedad, con base en tres aspectos que fundamentan su aplicación: 1) medidas referentes a ordenación, gestión y gobierno de los recursos materiales y humanos docentes; 2) finalidad y objetivos del aprendizaje por medio de los contenidos culturales y curriculares seleccionados, y 3) sistema axiológico, valores que justifican y sostienen cada uno de los sistemas educativos.

En todas las fases históricas se detectan carencias que limitan la igualdad real, pero en cada etapa la carencia se percibe en mayor grado basado en uno u otro aspecto:

Los Artículos 23, 24 y 25 de la Ley Orgánica 3/2007, del 22 de marzo, para la igualdad efectiva de mujeres y hombres disponen la integración de políticas de igualdad en el ámbito de la educación.

36 Larry Cuban, The Managerial Imperative and the Practice of Leadership in Schools (Albany: State University of New York, 1988). 
1. Medidas de gestión de recursos: en la fase inicial los recursos eran muy limitados y constituían un techo de arcilla estructural en la educación femenina. La mujer quedaba excluida o relegada frente al varón en los programas educativos. Se priorizaba la educación del varón porque estaba destinado a una función social pública. El debate, por tanto, se centraba en la coeducación por las carencias de infraestructuras para acoger a la población femenina en las aulas, lo que suscitaba la confrontación con los usos sociales y la mentalidad de la época.

2. La finalidad y los objetivos del aprendizaje referidos a contenidos formativos seleccionados, currículum, experiencias y oportunidades pedagógicas. A pesar del esfuerzo realizado durante el Gobierno franquista para universalizar y ampliar el período obligatorio de escolarización, la fractura social producida por la guerra civil hacía prioritario para el régimen la imposición de contenidos diferenciados por sexo e ideológicamente sesgados frente a la calidad pedagógica. Se implantó el pensamiento único y se orientó a varones y mujeres hacia un rol social consuetudinario, que limitó y disuadió las expectativas vitales de las mujeres y las orientó al desarrollo exclusivo hacia el ámbito familiar y doméstico. Techo de arcilla superado en la fase constitucional o igualitaria.

3. Valores: son los principios que fundamentan determinado sistema educativo. Estos valores, techos de arcilla invisibles, modelan la educación y la justifican; puede ser, por ejemplo, excluyente o restrictiva, en función de méritos, aptitudes, capacidad económica o sexo. Durante la fase inicial y regresiva se argumentó el determinismo biológico como límite a la educación femenina. En la fase constitucional, la educación se democratizó, la enseñanza media se hizo universal e inclusiva, el Estado garantizó su prestación y aspiró a una educación de calidad y equitativa. Estos valores han otorgado a la mujer el igual acceso a la educación y a las mismas oportunidades que el varón, pero no ha producido la trasformación cultural en cuanto al reparto de roles en el ámbito doméstico.

Se observa que cuando se detectan valores ausentes —al silenciar las diferenciaslas mejores intenciones como la igualdad efectiva quedan en simple retórica. La asignatura pendiente es, por tanto, destacar la importancia de las diferencias que suponen la futura maternidad y paternidad de los alumnos y enseñar lo que significa la corresponsabilidad en la faceta doméstica —omitida en la educación oficial—. El hogar es el punto de partida en donde se gestan las desigualdades de oportunidades entre varones y mujeres. Es necesario poner los recursos materiales, humanos y los contenidos curriculares alineados con el valor de la corresponsabilidad. 
El objetivo ahora es enseñar aquellos valores que puedan transformar y mejorar la sociedad para hacerla más justa. La cuestión surge sobre el sujeto responsable de la educación en valores: ¿El protagonismo lo ejercen los padres, que repiten los mismos valores y roles de actuación aprendidos o el Estado, por pasar a ser garante del sistema educativo en vez de subsidiario de los padres?

La ausencia en el modelo educativo actual del valor de la corresponsabilidad y del desarrollo de la inteligencia de género, referido a diferencias innatas o congénitas que tienen varones y mujeres, ${ }^{37}$ limita el cambio cultural necesario para implementar el modelo de corresponsabilidad entre varón y mujer.

Consideramos que el cambio de mentalidad, a partir de un modelo igualitarista o asimilacionista, requiere el modelaje educativo al menos por cuatro vías: la familia, las leyes educativas, la educación formal y la educación informal.

El objetivo no es otro que concienciar y visibilizar derechos que se derivan de los Artículos 1 y 2 de la Declaración universal de los derechos humanos, con el fin de lograr un mundo más justo y equitativo, donde la igualdad de responsabilidades y posibilidades entre mujeres y varones sea una realidad en todos los ámbitos, sobre todo en el seno de las familias.

\section{Referencias}

Bonino, Luis. "Los micromachismos", La Cibeles, núm. 2 (2004): 1-6.

Capel Martínez, Rosa María. El trabajo y la educación de la mujer en España (1900-1930), $2 a$ ed. Madrid: Ministerio de Cultura, 1986.

Castilla y Cortázar, Blanca. Persona y género. Ser varón y ser mujer. Madrid: Ediciones internacionales universitarias, 1997.

Cuban, Larry. The Managerial Imperative and the Practice of Leadership in Schools. Albany: State University of New York, 1988.

Chinchilla, Nuria, Esther Jiménez y Marc Grau. Maternidad y trayectoria profesional en España. Pamplona: Universidad de Navarra, 2017.

De Beauvoir, Simone. Le deuxième sexe. París: Gallimard, 1949.

Del Amo, María Cruz. "La educación de las mujeres en España: de la amiga a la universidad". Participación educativa, núm. 11 (2009): 8-22.

37 Natalia López Moratalla, Cerebro de mujer, cerebro de varón (Madrid: Rialp, 2007). 
Del Rincón, María Fernanda. "Mujeres azules de la Sección Femenina: formación, libros y bibliotecas para el adoctrinamiento político en España (1939-1945)”. MÉI: Métodos de información I, núm. 1 (2010): 59-81.

Del Valle Loroño, Ana Irene. "Inercias de género en la gestión de la vida profesional y familiar. Dos generaciones de familias de doble carrera". Tesis doctoral, Universidad de Deusto, 2016.

Durán y Lalaguna, Paloma. Los límites del derecho. Granada: Comares, 1996.

Elósegui Itxaso, María. "Educar en la corresponsabilidad entre mujeres y hombres. La igualdad necesaria". Revista General de Derecho Canónico y Derecho Eclesiástico del Estado, núm. 20 (2009): 1-28.

Elósegui Itxaso, María. Diez temas de género. Hombres y mujeres ante los derechos productivos y reproductivos. Madrid: Ediciones Internacionales Universitarias, 2011.

España. "Fuero de los españoles". Madrid: Boletín Oficial del Estado No. 199, 18 de julio de 1945.

España. Constitución Política. Madrid: Tecnos, 1931.

Fung, Archon y Erik Olin Wright. Deepening Democracy. Institutional Innovations in Empowered Participatory Governance. Nueva York: Verso, 2003.

López Moratalla, Natalia. Cerebro de mujer, cerebro de varón. Madrid: Rialp, 2007.

Martínez Priego, Consuelo. "Dinamismo familiar interno" en La familia y sus ámbitos. Cinco ensayos en torno a la familia desde la persona, editado por Consuelo Martínez Priego y Miguel Ruenmayor, 25-58. Ciudad de México: Porrúa, 2016.

Ministerio de Educación y Cultura y Deporte. Evolución del sistema educativo español. Madrid: Autor, 2004.

Ministerio de Educación. La educación en España (base para una política educativa). Madrid: Autor, 1969.

Pablo VI. Dignitatis Humanae. Concilio Vaticano II. Roma, 7 de diciembre de 1965.

Rebollo Mesas, Pilar. "El servicio social de la mujer de Sección Femenina de Falange. Su implantación en el medio rural" en Nuevas tendencias historiográficas e historia local en España, coordinado por Miguel Ángel Ruiz Carnicer y Carmen Frías Corredor, 297-316. Huesca: Universidad de Zaragoza, 2001.

Sáez Lara, Carmen. Mujeres y mercado de trabajo: las discriminaciones directas e indirectas. Madrid: Consejo Económico y Social de España, 1994. 